\title{
Influence of the North Atlantic Oscillation on the Canary Islands Precipitation
}

\author{
Ricardo García Herrera, David Gallego Puyol, and Emiliano Hernández Martín \\ Departamento de Física de la Tierra II, Facultad de Ciencias Físicas, Universidad Complutense de Madrid, Madrid, Spain \\ Luis Gimeno Presa And Pedro Ribera Rodríguez \\ Campus As Lagoas, Universidad de Vigo, Ourense, Spain
}

(Manuscript received 15 September 2000, in final form 24 January 2001)

\begin{abstract}
The aim of this paper is to investigate the relationship between the Canary Island rainfall and the Atlantic large-scale circulation, characterized by the North Atlantic oscillation (NAO) index. The Canary Islands are located in the Atlantic subtropical belt under the direct influence of the Azores high and the trade winds. Their steep orography makes the islands very sensitive to small variations in a synoptic situation, thus providing an excellent natural observatory for the North Atlantic variability associated with changes in pressure patterns.

A significant relationship between rainfall and the NAO is found for five of the seven Canary Islands. In order to characterize the physical mechanisms involved, a set of automatic objective techniques for identification and detection of disturbances is applied to the 1000- and 500-hPa geopotential from the NCEP-NCAR reanalysis for the period from 1955 to 1998 . This method allows for the identification and detection of four main synoptic systems-either at the surface or at $500 \mathrm{hPa}$ - that are responsible for $80 \%$ of the precipitation over the Canary Islands: Atlantic surface lows (ASLs), 500-hPa lows (UALs), 500-hPa troughs over the Canary Islands (TROs), and deep Atlantic lows (DALs), which affect the entire troposphere. Three of the detected disturbances (ASLs, TROs, and DALs) exhibit a dipolar structure with a low pressure center over $35^{\circ} \mathrm{N}$ associated with a positive anomaly at higher latitudes, resembling the NAO negative pattern. The analysis of the variability of the disturbance occurrence and the changes in their associated anomaly patterns shows that deeper and more frequent ASLs and TROs affect the Canary Islands during the negative phase of the NAO. However, UAL disturbances are less frequent, and DALs do not exhibit significant variations with the NAO phase.

The standard deviation of the 2.5-8-day bandpass-filtered geopotential height shows that the maximum variability associated with the NAO occurs over the Canary Island area, confirming its sensitivity to NAO variations.

The study provides a comprehensive view of the mechanisms involved in the precipitation generation over the Canary Islands, documenting a sensitivity to the NAO influences for a group of islands that have been poorly studied so far.
\end{abstract}

\section{Introduction}

The North Atlantic oscillation (NAO) (Walker and Bliss 1932) is the dominant mode of winter climate variability in the North Atlantic area on monthly to decadal timescales. There is great evidence of the NAO effects on many regions and variables: changes in the surface westerlies across the Atlantic into Europe (van Loon and Rogers 1978), precipitation (Hurrell 1995a; Ulbrich et al. 1999; Zorita et al. 1992; Lamb 1978; Folland et al. 1986; Lamb and Peppler 1987), changes in the Atlantic storm tracks or frequency (Rogers 1990, 1997; Hurrell 1995b; Serreze et al. 1997), temperature (Parker and Folland 1988; van Loon and Williams 1976;

Corresponding author address: Ricardo García Herrera, Departamento de Física de la Tierra II, Facultad de Ciencias Físicas, Universidad Complutense de Madrid, Ciudad Universitaria, 28040 Madrid, Spain.

E-mail: rgarcia@6000aire.fis.ucm.es
Moses et al. 1987; Wallace et al. 1995; Hurrell 1996) or SST, and salinity (Reverdin et al. 1997; Molinari et al. 1997).

The standard NAO index is usually computed as the sea level pressure (SLP) anomaly difference between the Azores and Iceland. A positive (negative) NAO index is connected with a stronger (weaker) than normal Azores high and Icelandic low. Therefore, a positive $\mathrm{NAO}$ phase $(\mathrm{NAO}+$ hereinafter) implies strengthened westerly winds across the midlatitude North Atlantic, leading to mild and wet winters in northern Europe (van Loon and Rogers 1978).

The NAO influence over the subtropical North Atlantic precipitation however is still poorly known because of the absence of long and reliable climatic time series in the area. Moreover, in case that such time series are available, they are usually affected by high noise levels due to the low precipitation rates in the subsidence belt associated with the Azores high. This paper ana- 


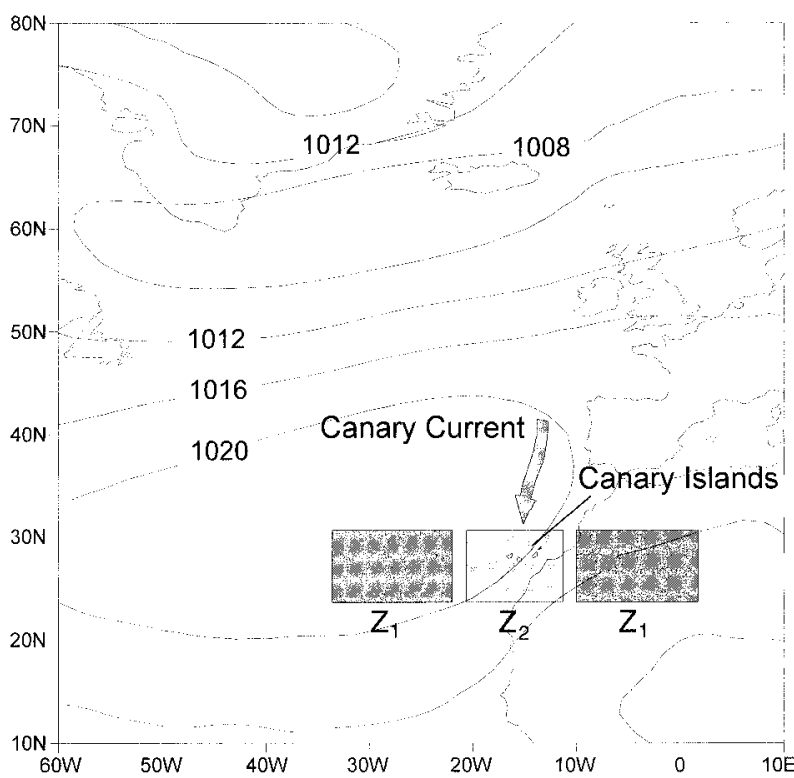

FIG. 1. Location of the Canary Islands. Daily averaged SLP (hPa) for the period from 1955 to 1998 and Canaries Current situation have been displayed. Shaded areas marked as $\mathrm{Z}_{1}$ and $\mathrm{Z}_{2}$ are those used in the trough detection method (see section 4).

lyzes precipitation series from the Canary Islands, which are located at $28^{\circ} \mathrm{N}$ latitude, under the direct influence of the Azores high. The combined effect of the ocean currents, trade winds, and the abrupt orography makes these islands much wetter than what is usual at this latitude. Moreover, the islands' precipitation is very sensitive to small changes in the atmospheric circulation, which has been evidenced by the presence of a significant ENSO teleconnection in an area where it had not been detected before (Gallego et al. 2001). In addition, the rainy season on Canary Islands ranges from November to March when the NAO is usually most pronounced.

The paper is organized in six sections as follows. After the introduction, section 2 provides a brief description of the islands and their climate. In section 3 , the precipitation time series used in this work are described. Section 4 is devoted to the detection and analysis of synoptic disturbances leading to precipitation in the islands. In section 5, the association among the $\mathrm{NAO}$, precipitation, and disturbances is investigated. Section 6 contains the discussion of the results.

\section{Canary Islands climate overview}

The Canary archipelago, which is located west of North Africa, consists of seven islands with a total area of about $7200 \mathrm{~km}^{2}, 1100 \mathrm{~km}$ away from the Spanish mainland. Reaching from $27^{\circ} 37^{\prime}$ to $29^{\circ} 25^{\prime} \mathrm{N}$ and from $18^{\circ} 10^{\prime}$ to $13^{\circ} 20^{\prime} \mathrm{W}$, all islands belong to the subtropical zone (Fig. 1).

From west to east the seven islands are as follows.
El Hierro is the smallest one $\left(224 \mathrm{~km}^{2}\right)$, but the third highest $(1501 \mathrm{~m})$ of the islands. La Palma, which is a very steep island and whose main geographical characteristic is a huge depression in its center, has leafy forests and is the second highest in the archipelago (2312 m). Gomera, which is nearly circular and raises up to $1487 \mathrm{~m}$ toward the center, has deep gullies and is the only island not having relatively recent volcanism. Tenerife, the largest island $\left(1929 \mathrm{~km}^{2}\right)$, possesses one of the highest volcanoes in the Northern Hemisphere, named "El Teide" and whose top is frequently covered by snow. Gran Canaria, another circular shaped island, reaches its highest point at its center (1949 m). Despite their volcanic origin, Fuerteventura and Lanzarote, the islands closest to the African coast $(100 \mathrm{~km})$, have a flatter relief, with altitudes below $700 \mathrm{~m}$.

The Canary Islands are under the direct influence of the trade wind belt, making the climate very stable all year. Usually, the Azores high acts as a shield, preventing Atlantic lows from affecting the area south of $30^{\circ} \mathrm{N}$. Moreover the islands are surrounded by a cold current named the Canaries Current, coming from the north as a derivation of the Gulf Stream. The average trade winds blow mainly against the north side of the islands, advecting wet and fresh air, which can rise over the island slopes, often leading to condensation and cloud growth that is usually obstructed by the typical vertical stratification structure (Font 1956). Three main layers can be distinguished: 1) Relatively fresh and moist air exists at low levels, due to the cold surface water of the Canaries Current. 2) Roughly between 700 and $1500 \mathrm{~m}$ a subsidence inversion is usually found. Temperature increases across this layer up to $6^{\circ} \mathrm{C}$, acting as a lid that obstructs any convective development, even those forced by the terrain. 3) Over the inversion layer, the air is dry and clear. In this way, water vapor is condensed at low levels, under the inversion layer, developing nonprecipitating thin clouds, which are called "cloud sea" when viewed from above the clouds' top.

Therefore the typical weather on the Canary Islands is very stable and dry. Rainy events only happen when disturbances break the inversion layer, either at surface (Atlantic lows) or at upper levels (troughs). The importance of high-level disturbances on the islands' precipitation must be emphasized. Most of the typical rainfall situations cannot be detected at surface level, and are only evident when upper levels are analyzed.

\section{a. Relief influence}

Relief is the main factor that affects the local rainfall distribution. A typical example of the orographic influence can be seen in Fig. 2, which displays a north-south section through Tenerife with the annual pluviograms for four selected stations. The station located at the northern slope (B station) is the wettest, followed by high mountain station $\mathrm{C}$. Station $\mathrm{A}$, which is located at 

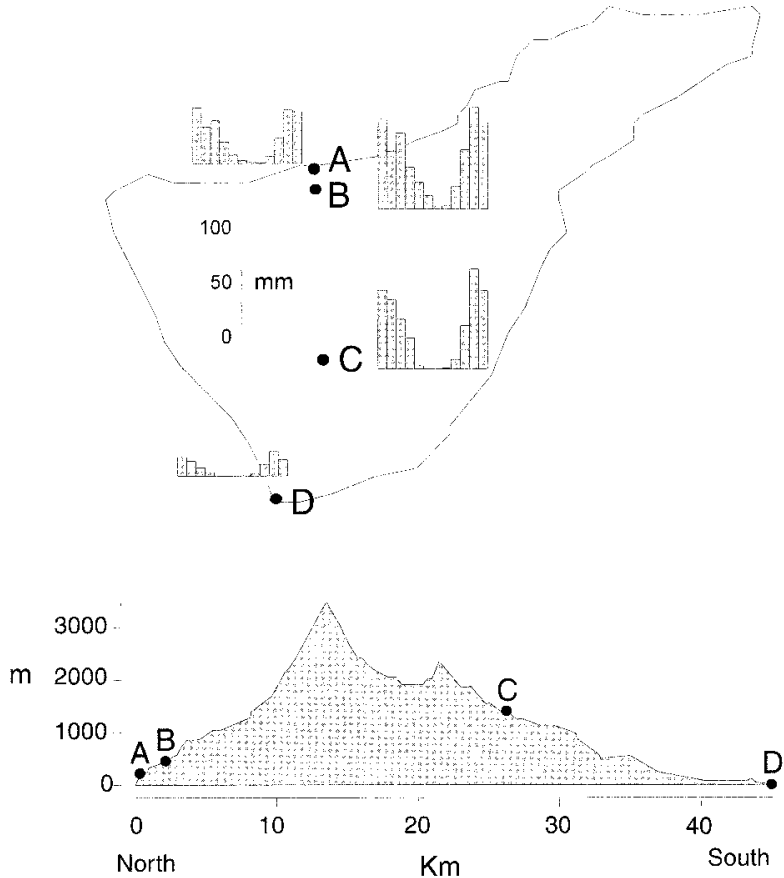

FIG. 2. An example of the relief influence on precipitation regime in Tenerife Island. (top) Monthly pluviograms for four selected stations. (bottom) The altitudinal profile of the island.

the north coast, reveals an intermediate behavior, while station D, at the southern coast, is clearly the driest.

In general, precipitation increases across the archipelago from east to west (Fig. 3). Three groups of islands can be distinguished: La Palma and El Hierro are the wettest with more than $700 \mathrm{~mm}$ over much of its area, preferably at their northern sides. Frequencies of about 50 precipitation days are usually found. Gomera, Tenerife, and Gran Canaria form a second group. In these islands, the rainfall structure is clearly connected to the relief, showing maximum rainfall of up to 500 $\mathrm{mm}$ and frequencies of up to 65 days at the northern side. The southern side is drier with precipitation of 200 $\mathrm{mm}$ and frequencies of about 20 days. In contrast to that, Lanzarote and Fuerteventura are quite arid, with annual precipitation below $200 \mathrm{~mm}$ over its entire surface, forming a third and very different cluster.

\section{b. Temporal distribution}

Island-averaged precipitation regimes similarly show a strong seasonality (Fig. 3a) with maximum monthly rainfall between 30 (Lanzarote and Fuerteventura) and $100 \mathrm{~mm}$ (wettest islands) during autumn and winter and relatively dry or even rainless months from April to September.

\section{Precipitation time series}

Precipitation data from 63 monthly and eight daily stations were selected from the Spanish Meteorological
Institute (INM) archives by considering quality, distribution, and length (Fig. 4). Monthly stations are regularly distributed. Daily stations' distribution is sparse, with no coverage for Hierro and Gomera and only one station on La Palma.

Raw monthly time series exhibit some gaps, and time coverage varies strongly from station to station. This fact makes it inadvisable to directly apply usual statistical methods to obtain the principal modes of variability and their corresponding temporal series such as an empirical orthogonal function (EOF) analysis (Kutzbach 1967; Preisendorfer 1988). Although precipitation amounts strongly depend on the location of the station within an island, their temporal behavior is very similar. In fact, the typical correlation coefficient between monthly station series inside an island is about 0.8 , indicating that all the stations inside an island are displaying the same mode of variability. In order to avoid the problem of the different period covered by the raw series and to obtain time series representing the whole rainfall for each island, a weighting procedure was developed. First, annual precipitation series for hydrologic years (from September to August) were computed for the whole period, replacing missing data by the corresponding monthly average. Years with more than one missing rainy month (i.e., from September to March) were excluded to minimize artificial noise levels. The weighting procedure consists of three steps:

1) For each island, only stations sharing a period of at least $15 \mathrm{yr}$ were included into the weighting algorithm. This step allows one to reject stations with most of their valid data isolated from the rest, which makes it difficult to estimate the relative importance of the station for the overall rainfall of the respective island.

2) For the selected stations, the annual total amount of precipitation $P_{\text {island }}=\Sigma P_{\text {stations }}$ was computed in order to calculate its annual contribution to the total island rainfall $C_{\text {station }}=P_{\text {station }} / P_{\text {island }}$.

3) The average $C_{\text {station }}$ values for the total period were used as the weighting coefficients to estimate the total island precipitation.

To test the reliability of this method, a correlation analysis between the reconstructed time series and nonweighted sum of annual station series was performed when possible (i.e., for years with actual data available for every station). The correlation coefficient was greater than $0.99(p<0.01)$ in all cases. This procedure allows for the reconstruction of the precipitation time series representing a whole island from individual series with relatively sparse time coverage without adding too much noise to the reconstructed series. Typically, only $10 \%$ of the resulting time series stem from reconstructed data. Table 1 shows the time coverage and the missing years for every island.

The eight daily time series were used in raw form (Table 2); no reconstruction method was used in this 
(a) Annual precipitation and precipitation regime $(\mathrm{mm})$

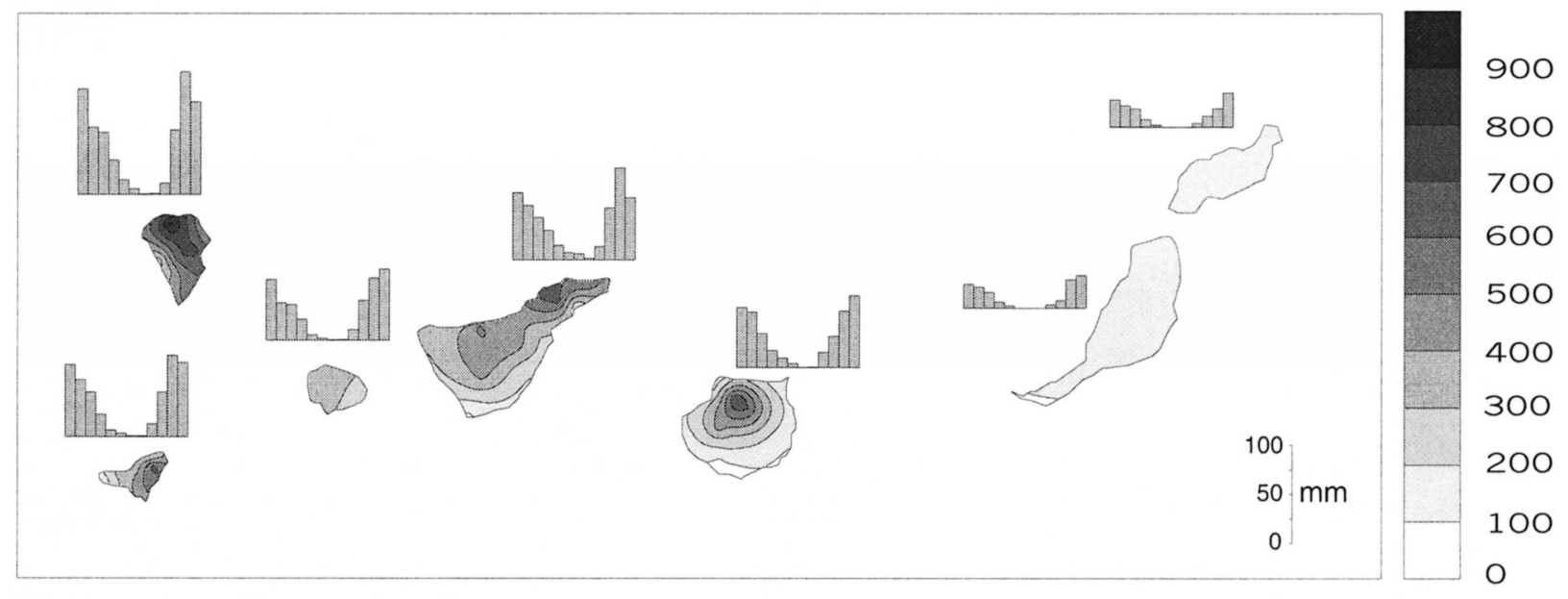

\section{(b) Annual precipitation days}

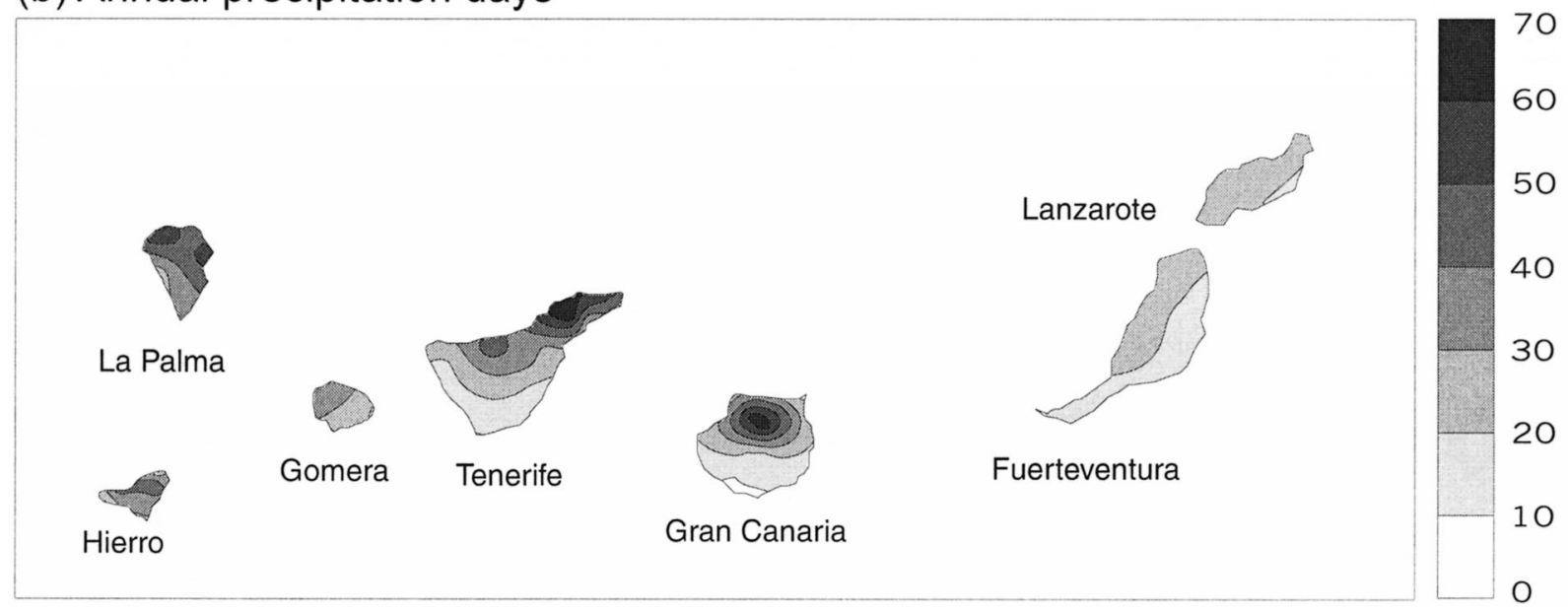

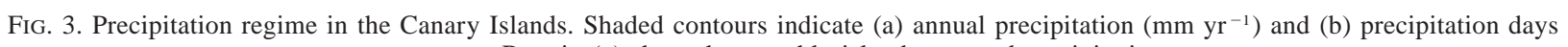
per year. Bars in (a) show the monthly island-averaged precipitation.

case. All the stations but Tenerife (13.4\%) have less than $6.2 \%$ missing days.

\section{Synoptic disturbances \\ a. Detection procedure}

In section 2, the importance of Atlantic lows and highlevel troughs for the rainfall generation over the islands has been outlined. In order to obtain an objective detection method for these patterns, daily geopotential heights (1200 UTC) from the National Centers for Environmental Prediction-National Center for Atmospheric Research (NCEP-NCAR) reanalysis (Kalnay et al. 1996), available for the period from 1955 to 1998 on a $2.5^{\circ}$ grid from $15^{\circ}$ to $55^{\circ} \mathrm{N}$ and from $50^{\circ}$ to $10^{\circ} \mathrm{E}$ have been used. Original 1000-hPa geopotential heights were transformed into SLP through: SLP $(\mathrm{hPa})=0.123 Z_{1000}$ $(\mathrm{gpm})+1000$ (Peixoto and Oort 1992).
The algorithm used to detect closed lows follows the one described in previous works (Blender et al. 1997). A grid point must fulfill three conditions to be classified as a low: 1) A local minimum over a $3 \times 3$ point array, 2) a value below $1020 \mathrm{hPa}$ for the surface and below $5900 \mathrm{gpm}$ for $500 \mathrm{hPa}$, and 3) An average gradient over a $5 \times 5$ point array $(1000 \mathrm{~km}$ around the center $)$ of at least $0.45 \mathrm{hPa}(100 \mathrm{~km})^{-1}$ (surface) or $4.0 \mathrm{gpm}(100$ $\mathrm{km})^{-1}(500 \mathrm{hPa})$.

These thresholds were chosen empirically after a subjective analysis carried out for January, April, and August 1979 to avoid seasonal effects resulting in surface thresholds slightly relaxed as compared with similar studies (Trigo et al. 1999), due to the coarser resolution $\left(2.5^{\circ} \times 2.5^{\circ}\right.$ instead of $\left.1.125^{\circ} \times 1.125^{\circ}\right)$ and the more southern latitude. A success rate from $90 \%$ to $95 \%$, tested by visual subjective analysis, was obtained.

The preceding method is not able to detect open 500- 


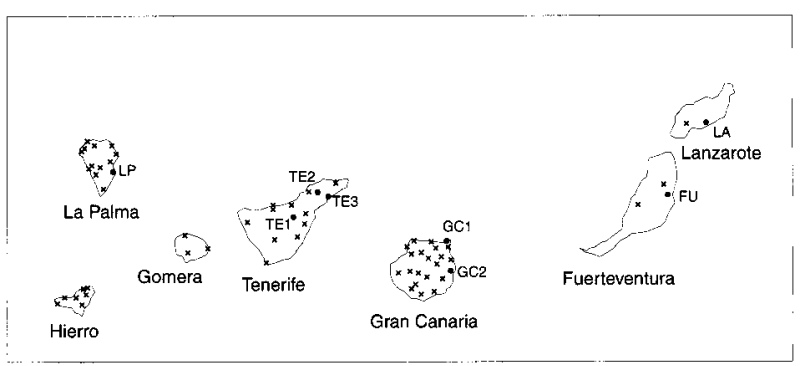

FIG. 4. Location of selected Canarian rainfall stations used in the study. Monthly and daily stations are marked as crosses and dots, respectively. Daily stations are identified by the island initials (if more than one, they are numbered consecutively eastward).

$\mathrm{hPa}$ troughs. Since these synoptic perturbations are a significant precipitation generator for the Canary Islands, a new algorithm has been developed for their detection. The averaged 500-hPa geopotential height over 12 grid points directly over the Canary Island (gray rectangle marked as $Z_{2}$ in Fig. 1) was compared with the mean geopotential over the surrounding 30 grid points at the same latitudinal belt (dark areas marked as $Z_{1}$ in Fig. 1). If the difference between both means was greater than $25 \mathrm{gpm}$ we assumed a relative strong trough over the Canary Island, so that the day was considered a "trough day." Again, both the selected areas and the detection threshold were chosen empirically in order to obtain the maximum detection rate (nearly $90 \%$ was achieved).

Direct application of the low-detection method results in a series of Atlantic lows specified by latitude, longitude, and date. The study area allows for obtaining results from $20^{\circ}$ to $50^{\circ} \mathrm{N}$ and from $45^{\circ}$ to $5^{\circ} \mathrm{E}$. In order to determine the low-influence zone for the Canary Islands, a "low day with precipitation" was defined as every day when a low was detected and, simultaneously, precipitation was recorded on at least one of the islands. For every grid point the rate between the number of "low days with precipitation" and the total number of days when a low was detected over the grid point was computed as the "precipitation effectivity index." According to the total percentage of precipitation days, a pure random effectivity index of $34 \%$ would be expected independently of synoptic situation (the empirical probability for "precipitation day" in any island). It should be pointed out that the probability of $34 \%$ for a pre-
TABle 1. Time coverage for the Canarian reconstructed annual rainfall time series.

\begin{tabular}{lcl}
\hline \hline \multicolumn{1}{c}{ Island } & Period & \multicolumn{1}{c}{ Missing years } \\
\hline Hierro & $1949-98$ & \\
La Palma & $1935-98$ & \\
Gomera & $1948-98$ & $1951,1952,1955-61,1967,1968$ \\
Tenerife & $1901-98$ & 1915,1916 \\
Gran Canaria & $1952-98$ & \\
Fuerteventura & $1953-98$ & \\
Lanzarote & $1957-98$ & $1962-67,1970$ \\
\hline
\end{tabular}

cipitation day is the probability of rain occurrence over at least one of the stations across the islands. This would imply an average of about 124 rainy days $\mathrm{yr}^{-1}$. Results in Fig. 3 (with maximum below 70 days) are expressed in days $\mathrm{yr}^{-1}$, but only for individual locations, not for the whole archipelago. After different a posteriori trials, an optimal value of $50 \%$ was chosen as a threshold to determine the points within the precipitation effectivity area (see section $4 \mathrm{~b}$ for further details). Figure 5 shows these areas for the surface and the 500-hPa level. For our purposes, a day was classified as a "low day" over the Canary Islands - either at surface or at $500 \mathrm{hPa}-$ when a low was detected in the area where the "precipitation effectivity" is higher than $50 \%$. At the surface, a zone of effectivity greater than $80 \%$ can be seen at the north side of the archipelago, centered at $30^{\circ} \mathrm{N}$, $15^{\circ} \mathrm{W}$. It shows a SW-NE orientation, according to the usual path of the Atlantic lows at this latitude (Ulbrich et al. 1999). The 50\% effectivity zone at the surface level is very wide covering longitudes from $30^{\circ} \mathrm{W}$ to $5^{\circ} \mathrm{E}$ and was divided into two parts due to the different situations involved. The first sector, covering the 50\% zone west of $7.5^{\circ} \mathrm{W}$, delimits the direct influence area of Atlantic lows and its associated fronts. Lows detected in this area were named Atlantic surface lows (ASLs). The $50 \%$ zone east of $7.5^{\circ} \mathrm{W}$ corresponds to surface lows over the Mediterranean and northern Africa areas, which are related with cold and wet air fluxes coming from the north over the archipelago, this situation is often coincident with troughs on $500 \mathrm{hPa}$ over the Canary Islands. The 500-hPa effectivity index map is similar but with lower values, the maximum is found directly over the islands reaching to, at most, $60 \%$.

It has been shown that the direct application of this set of detection methods is able to categorize a day as

TABLE 2. Time coverage and missing data (\%) for the daily stations. (See Fig. 4 for station location.)

\begin{tabular}{|c|c|c|c|}
\hline Island & Station & Time coverage & $\%$ missing data \\
\hline La Palma (LP) & LP & 1 Apr 1970-31 Dec 1998 & 2.1 \\
\hline \multirow[t]{3}{*}{ Tenerife (TE) } & TE1 & 1 Jan 1948-30 Nov 1998 & 6.2 \\
\hline & TE2 & 11 Jan 1951-31 Dec 1998 & 13.4 \\
\hline & TE3 & 1 Jan 1943-31 Dec 1998 & 0 \\
\hline \multirow[t]{2}{*}{ Gran Canaria (GC) } & GC1 & 1 Jan 1950-30 Jun 1994 & 0.4 \\
\hline & GC2 & 11 Jan 1951-31 Dec 1998 & 5.5 \\
\hline Fuerteventura (FU) & FU & 1 Oct 1969-31 Dec 1998 & 0 \\
\hline Lanzarote (LA) & LA & 1 Nov 1972-31 Dec 1998 & 0 \\
\hline
\end{tabular}



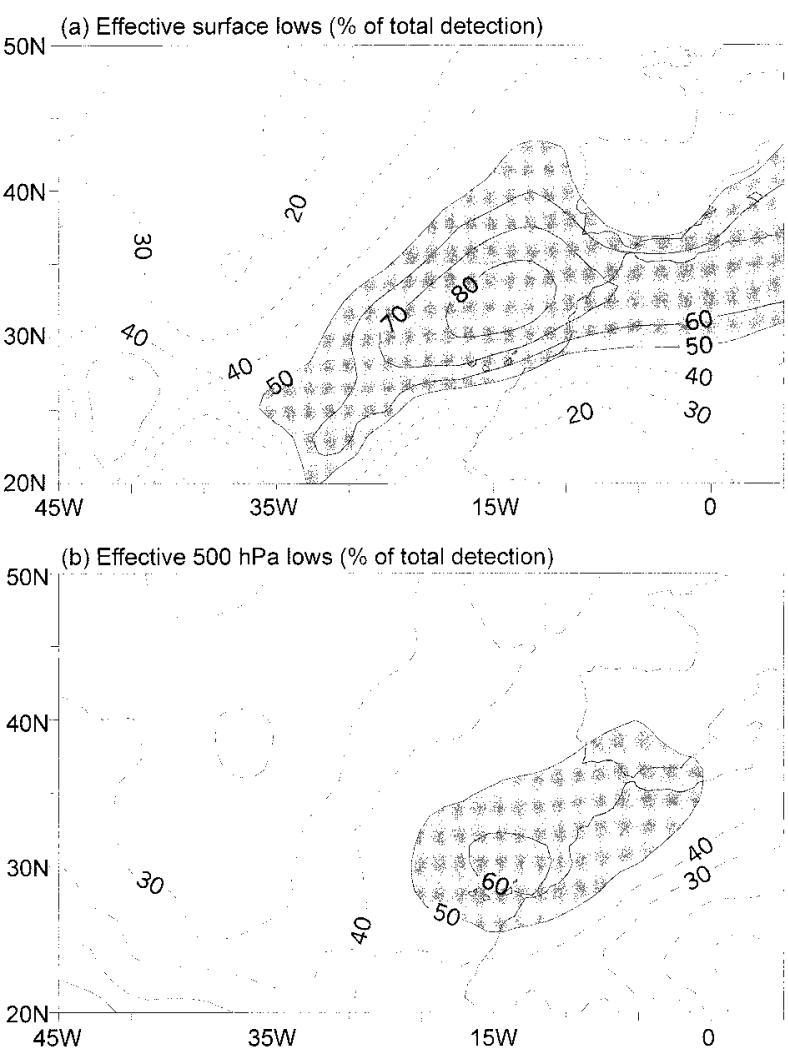

FIG. 5. Low-effectivity index, defined as the percentage of days that a closed low has been detected and simultaneous precipitation has been measured on at least one of the islands. A value of $34 \%$ indicates a random relation. Values above $50 \%$ determine the lowinfluence area used to classify the precipitation character (shadowed area). Values lower than $50 \%$ are dashed.

ASL, Mediterranean surface low (MSL), upper-air low (UAL), or upper-air trough (TRO). So far it does not contain any limitation for coincident detection. To obtain a mutually excluding characterization, the priority criteria shown in Table 3 has been applied hierarchically after the detection routines, thus assuring that any day is classified in at least one of the categories shown in Table 4. A new type of disturbance has been defined as deep Atlantic lows (DALs) when closed lows were found simultaneously over the Atlantic influence area at the surface and at $500 \mathrm{hPa}$.

To test the dependence on the dataset, the same method has been applied for the period 1979-93 to the sameresolution reanalysis dataset provided by the European Centre for Medium-Range Weather Forecasts (ECMWF; Gibson et al. 1997). Essentially the same results have been obtained.

\section{b. Influence of the disturbances on precipitation}

It must be checked if the selected classification adequately represents the Canary rainfall. Table 5 shows the statistics (detached by disturbance type) for the following values: the percentage of rain occurrence on all
TABLE 3. Priority criteria employed to filter multiple detection.

\begin{tabular}{ccc}
\hline \hline Order & Simultaneous detection & $\begin{array}{c}\text { Codified } \\
\text { category }\end{array}$ \\
\hline 1 & $\begin{array}{c}\text { Atlantic low on surface and 500 hPa (inde- } \\
\text { pendent of any other detection) }\end{array}$ & DAL \\
2 & $\begin{array}{c}\text { Surface low over the Atlantic area plus any } \\
\text { other detection not included in 1 }\end{array}$ & ASL \\
3 & $\begin{array}{c}500-\mathrm{hPa} \text { low plus any other detection not in- } \\
\text { cluded in 1 }\end{array}$ & UAL \\
4 & $\begin{array}{c}\text { Mediterranean surface low and 500-hPa At- } \\
\text { lantic low }\end{array}$ & UAL \\
5 & $\begin{array}{c}\text { Mediterranean surface low and trough over } \\
\text { Canary Islands }\end{array}$ & TRO \\
6 & $\begin{array}{c}\text { 500-hPa Atlantic low and trough over Ca- } \\
\text { nary Islands }\end{array}$ & UAL \\
\hline
\end{tabular}

days when a certain disturbance was detected (PRO), the mean daily precipitation (MP), and the percentage of total precipitation (PTP) associated with each disturbance type. Results for the precipitation fallen during days when no system was detected (ND) are also included.

On average, almost $80 \%$ of total the total precipitation can be associated with one of the five detected disturbances. The criterion followed to select the influence area described in Fig. 5 was already the optimum value that could be achieved. In general the driest islands have the lowest number of nonclassified rainy days, while wetter islands exhibit the greatest values, as the Tenerife's mountain station TE2 and in La Palma, but in no case is the explained precipitation below $70 \%$. This fact suggests that on the flatter and drier islands, where relief is not a triggering factor, a well developed and more easily detectable synoptic system is needed for precipitation generation. In order to determine the extension of the influence zone of the different disturbance types and the relative importance of nonclassified days, the average number of stations simultaneously affected by rainfall events was computed on every daily station. Depending on disturbance type, an average number from 3.5 (for TROs and DALs) to 5 (to surface lows ASLs) stations exhibit rainfall simultaneously on classified days, while less than 2 stations present rainfall on ND days. So, precipitation on ND days is significantly lower and affects a smaller area. Therefore, the implemented detection algorithm works as expected, giving preference to the precipitation effects due to synoptic-scale disturbances.

Total rain distribution on classified days (PTP rows

TABLE 4. Final disturbance classification.

\begin{tabular}{ll}
\hline \hline Category & \multicolumn{1}{c}{ Disturbance type } \\
\hline ASL & Atlantic surface low \\
MSL & Mediterranean surface low \\
UAL & $500-$ hPa Atlantic low \\
TRO & $500-$ hPa trough \\
DAL & Deep Atlantic low \\
ND & No detection \\
\hline
\end{tabular}


TABLE 5. Percentage of rain occurrence depending on disturbance (PRO), mean daily precipitation (mm day ${ }^{-1}$ ) (MP), and percentage of total precipitation by disturbance type (PTP). Precipitation with no system detected are included (ND). See Fig. 4 for the station location.

\begin{tabular}{|c|c|c|c|c|c|c|c|c|c|c|}
\hline \multirow{2}{*}{\multicolumn{2}{|c|}{ Disturbance }} & \multicolumn{8}{|c|}{ Station } & \multirow{3}{*}{$\frac{\text { Average }}{12.0}$} \\
\hline & & \multirow{2}{*}{$\begin{array}{c}\text { LP } \\
10.8\end{array}$} & \multirow{2}{*}{$\begin{array}{l}\text { TE1 } \\
12.5\end{array}$} & \multirow{2}{*}{$\begin{array}{r}\text { TE2 } \\
9.9\end{array}$} & \multirow{2}{*}{$\begin{array}{c}\text { TE3 } \\
11.8\end{array}$} & \multirow{2}{*}{$\begin{array}{r}\text { GC1 } \\
8.7\end{array}$} & \multirow{2}{*}{$\frac{\mathrm{GC} 2}{10.6}$} & \multirow{2}{*}{$\frac{\mathrm{FU}}{16.2}$} & \multirow{2}{*}{$\frac{\text { LA }}{15.6}$} & \\
\hline ASL & PRO & & & & & & & & & \\
\hline & MP & 10.8 & 10.6 & 11.3 & 5.7 & 4.3 & 6.2 & 5.4 & 3.1 & 7.2 \\
\hline & PTP & 22.2 & 15.8 & 16.7 & 16.0 & 14.8 & 14.8 & 19.0 & 16.5 & 17.0 \\
\hline \multirow[t]{3}{*}{ MSL } & PRO & 3.3 & 3.7 & 4.1 & 4.2 & 4.3 & 4.3 & 3.2 & 5.1 & 4.0 \\
\hline & MP & 3.5 & 6.6 & 5.1 & 2.3 & 2.2 & 3.6 & 2.3 & 1.6 & 3.4 \\
\hline & РTP & 2.2 & 3.0 & 3.1 & 2.4 & 3.8 & 3.5 & 1.6 & 2.8 & 2.8 \\
\hline \multirow[t]{3}{*}{ UAL } & PRO & 16.9 & 23.3 & 19.3 & 21.5 & 21.4 & 22.6 & 22.6 & 22.4 & 21.2 \\
\hline & MP & 5.2 & 9.1 & 6.1 & 4.1 & 2.9 & 4.7 & 4.2 & 2.9 & 4.9 \\
\hline & PTP & 16.8 & 25.3 & 17.8 & 20.8 & 24.9 & 23.9 & 20.4 & 21.9 & 21.5 \\
\hline \multirow[t]{3}{*}{ TRO } & PRO & 12.4 & 17.0 & 13.0 & 14.5 & 13.8 & 14.4 & 13.9 & 13.0 & 14.0 \\
\hline & MP & 5.9 & 9.8 & 9.0 & 5.3 & 3.3 & 5.4 & 5.1 & 3.3 & 5.9 \\
\hline & PTP & 14.1 & 19.8 & 17.6 & 18.4 & 18.2 & 17.4 & 15.5 & 14.7 & 17.0 \\
\hline \multirow[t]{3}{*}{ DAL } & PRO & 8.5 & 11.4 & 7.5 & 10.0 & 8.6 & 10.7 & 20.6 & 16.1 & 11.7 \\
\hline & MP & 9.2 & 11.4 & 16.6 & 9.1 & 4.8 & 7.9 & 7.4 & 5.8 & 8.9 \\
\hline & РTP & 15.0 & 15.4 & 17.5 & 22.0 & 16.4 & 18.9 & 32.8 & 31.8 & 21.2 \\
\hline \multirow[t]{3}{*}{ ND } & PRO & 48.0 & 32.0 & 46.3 & 37.9 & 43.2 & 37.4 & 23.5 & 27.8 & 37.0 \\
\hline & MP & 3.3 & 5.4 & 4.0 & 2.3 & 1.3 & 2.6 & 2.1 & 1.3 & 2.8 \\
\hline & PTP & 29.8 & 20.7 & 27.4 & 20.5 & 22.0 & 21.5 & 10.9 & 12.4 & 20.7 \\
\hline
\end{tabular}

in Table 5) shows an interesting structure. On rainy islands (as La Palma, Tenerife, and even Gran Canaria), most of the classified rainfall is due to UALs with values around $20 \%$, reaching $25.3 \%$ at Tenerife's station TE1. However, these events are not the most intense (MP rows in Table 5), those being for most of the archipelago DAL disturbances, with an average value of $8.9 \mathrm{~mm}$ day $^{-1}$, reaching $16.6 \mathrm{~mm} \mathrm{day}^{-1}$ on TE2. ASL events, with $7.2 \mathrm{~mm} \mathrm{day}^{-1}$ on average, are the next in intensity, reaching values up to $10 \mathrm{~mm}$ day $^{-1}$ on three stations. TRO values confirm their importance on Canarian rainfall, with values comparable to the ASL and UAL. Mediterranean surface lows are usually related with the presence of cold air on upper levels over the Canary Islands (Font 1956). The filtering method employed to avoid duplicate detection gives preference to the last mechanism, classifying most of the Mediterranean lows as TROs or UALs Therefore, the low number of remaining Mediterranean lows accounts only for $3 \%$ of the total precipitation.

The different behavior of Lanzarote and Fuerteventura in relation to the rest of the archipelago concerns not only the rainfall amount, but also its distribution due to different disturbance types. Both of them exhibit very large values of precipitation due to DALs with more than $30 \%$ of its total (nearly double the other islands). Nonclassified days account only for $10 \%$ of total precipitation. The precipitation due to $500-\mathrm{hPa}$ disturbances (UALs and TROs) is as important as on the highest islands.

The synoptic origin of most of the Canary rainfall can also help to explain the differences in precipitation distribution between the islands. Correlation coefficients for the seven islands' annual reconstructed series are shown in Table 6. Annual behavior of the five western islands is very similar, with significant correlation ranging from 0.62 to 0.87 . Lanzarote and Fuerteventura, strongly correlated with each other $(r=0.70 ; p<0.01)$, exhibit lower correlations with the rest, forming an appreciably separated cluster.

Despite the relatively low correlation indexes of Lanzarote and Fuerteventura, processes yielding rainfall over them are not different in nature from those producing rainfall over the five western islands. An analysis of daily series shows that about $83 \%$ of rainy days on Fuerteventura or Lanzarote are rainy days on La Palma or Tenerife too. However, only $31 \%$ of days with precipitation on the western islands are rainy on the eastern

TABLE 6. Correlation between reconstructed rainfall time series of the Canary Islands (hydrological years from Sep to Aug).

\begin{tabular}{|c|c|c|c|c|c|c|}
\hline & Hierro & La Palma & Gomera & Tenerife & Gran Canaria & Fuerteventura \\
\hline La Palma & $0.84 * *$ & & & & & \\
\hline Gomera & $0.86^{* *}$ & $0.84^{* *} *$ & & & & \\
\hline Tenerife & $0.69 * *$ & $0.75 * *$ & $0.82 * *$ & & & \\
\hline Gran Canaria & $0.62 * *$ & $0.82 * *$ & $0.65 * *$ & $0.87 * *$ & & \\
\hline Fuerteventura & 0.27 & 0.29 & $0.36^{*}$ & $0.39 * *$ & $0.37 *$ & \\
\hline Lanzarote & 0.29 & $0.44 * *$ & 0.21 & $0.50 * *$ & $0.68 * *$ & $0.70 * *$ \\
\hline
\end{tabular}

* $95 \%$ significant correlation.

** $99 \%$ significant correlation. 
TABLE 7. Correlation between annual rainfall time series and NAO index (NAO index computed from Dec to Mar).

\begin{tabular}{ll}
\hline \hline \multicolumn{1}{c}{ Island } & Correlation \\
\hline Hierro & $-0.43^{*}$ \\
La Palma & $-0.49^{*}$ \\
Gomera & $-0.51^{*}$ \\
Tenerife & $-0.20^{*}$ \\
Gran Canaria & $-0.38^{*}$ \\
Fuerteventura & -0.04 \\
Lanzarote & -0.14 \\
\hline
\end{tabular}

* $99 \%$ significant correlation.

ones. This fact suggests that, though the precipitation episodes over the Canarian area usually affect the whole archipelago, they yield rainfall preferably on western islands. Two factors are involved in this distinctive behavior: 1) The maximum effectivity low area, so that the western islands are more frequently and directly affected by the frontal tails associated with surface disturbances that lose their effectivity farther east and 2) the flatter relief of Lanzarote and Fuerteventura, which requires deeper disturbances to yield rainfall.

\section{Canary rainfall and the North Atlantic oscillation}

In this section, a set of correlation analyses will provide a first overview of the statistical relationship between the NAO and the Canarian rainfall. Then, the physical mechanisms involved will be investigated by means of the study of the NAO influence on the occurrence, intensity, shape, and total rainfall recorded for each disturbance type.

NAO index data, computed as the normalized pressure differences between stations on SW Iceland and Gibraltar, have been taken from the Climatic Research Unit (Hurrell 1995a; Jones et al. 1997).

\section{a. Statistical correlations}

The reconstructed annual time series representing each island were correlated with the winter NAO index (winter considered as the December-March period from now on). The NAO influence on annual precipitation is evident (Table 7), especially for the rainy western islands, which exhibit significant negative correlation indexes ranging from -0.51 for Gomera to -0.38 for Gran Canaria.

To investigate if the standard NAO index is optimally representing the Canarian rainfall where high correlation has been found, the correlation indexes between precipitation and surface pressure for winter monthly series were computed over the North Atlantic area (U1brich et al. 1999). The three typical cases for La Palma (rainy islands with high NAO correlation), Lanzarote (representing the driest island without NAO correlation), and Gran Canaria as an intermediate case have been displayed in Fig. 6. The different NAO relationships are evident. On La Palma, the structure shown is almost identical to the canonical NAO dipole (Kushnir and Wallace 1989), with the negative correlation center only slightly displaced southward from the common NAO pole. Lanzarote's correlation still shows a dipolar pattern, but the negative correlation center is limited to a narrow area close to the islands and the northern pole consists of a broad area with correlation only slightly greater than 0.1. Gran Canaria's pattern is nearly dipolar, with the southern part of the dipole similar to the La Palma pattern although appreciably weaker, while the northern part is displaced southwestward, so that the dipole axis is directed from southwest to northeast. Results for Hierro, Gomera, and Tenerife are similar to that of La Palma, revealing a strong NAO influence on rainfall. Fuerteventura's correlation pattern is similar to the one for Lanzarote, while Gran Canaria's correlation pattern still resembles the NAO but with the poles displaced southward as compared with the common NAO centers. (a) La Palma

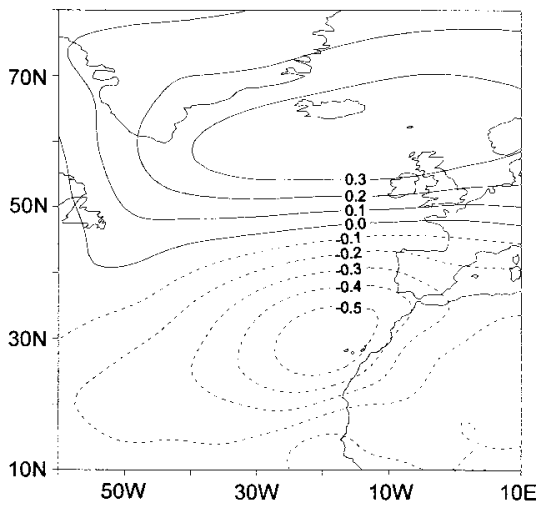

(b) Gran Canaria

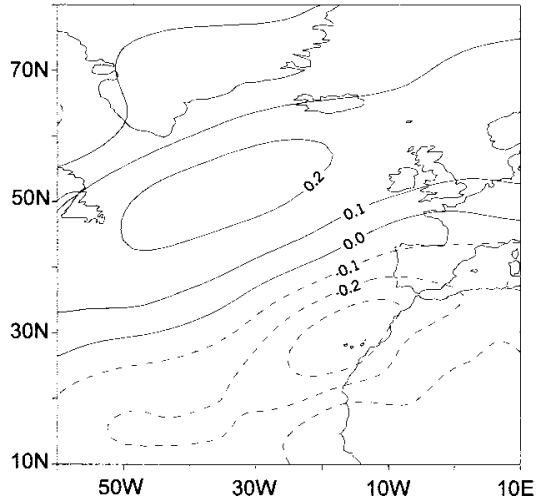

(c) Lanzarote

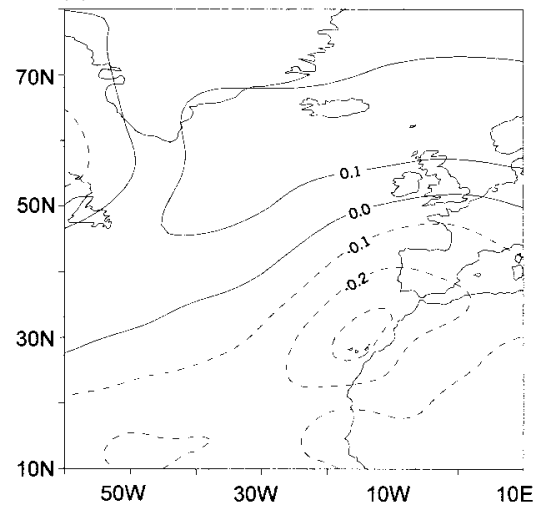

FIG. 6. Correlation pattern between monthly SLP and reconstructed rainfall series for (a) La Palma, (b) Gran Canaria, and (c) Lanzarote. Values above 0.15 for La Palma and Gran Canaria and above 0.16 for Lanzarote are significant $(p<0.05)$. 
(a) ASL frequency (events per year)

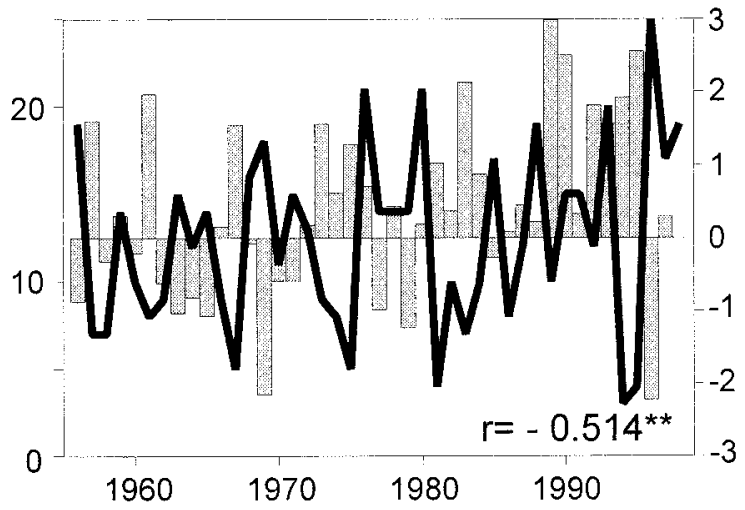

(c) UAL frequency (events per year)

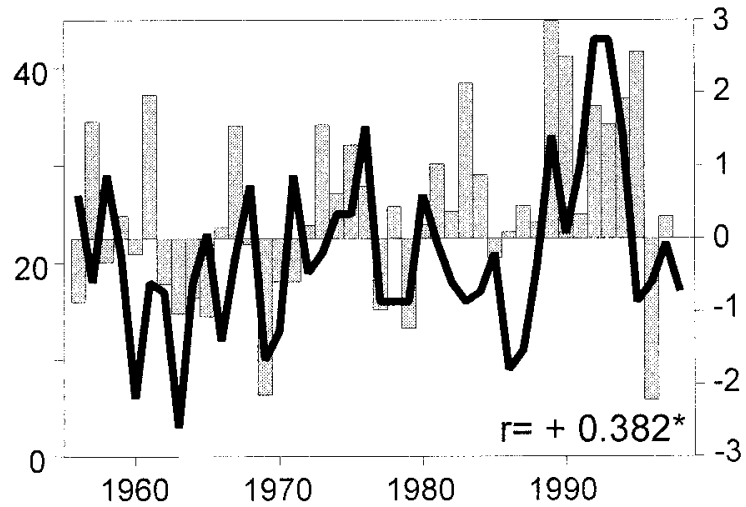

(b) ASL center average pressure ( $\mathrm{hPa}$ )

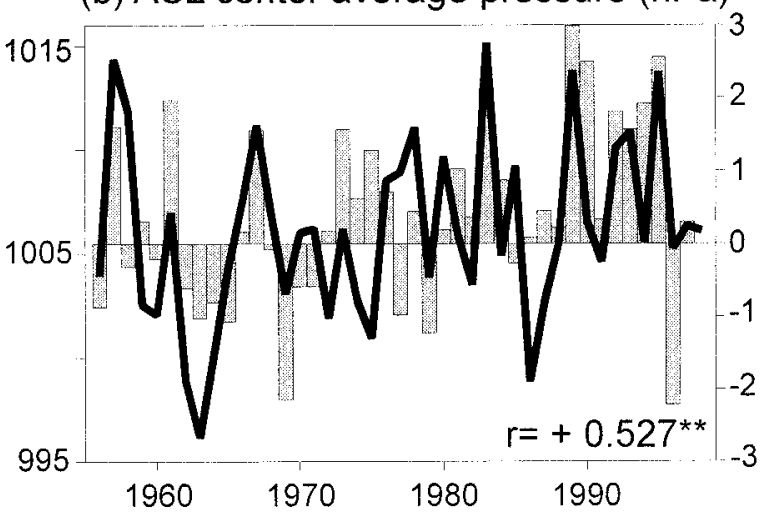

(d) UAL Center average height (mgp)

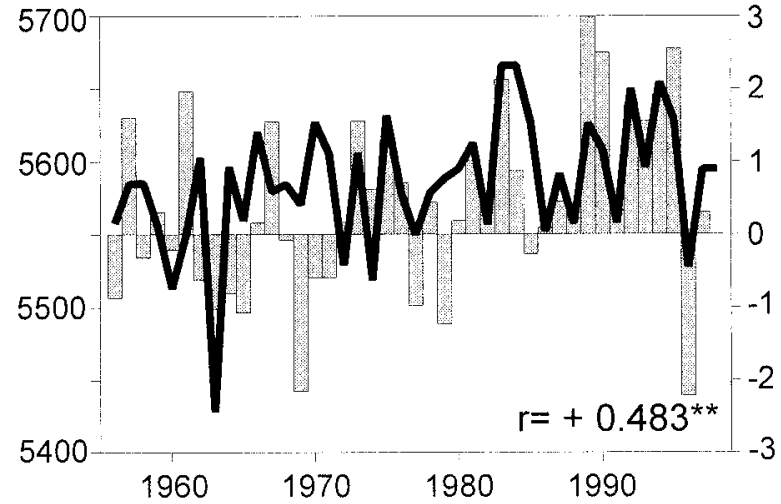

FIG. 7. Annual winter series for (a) Atlantic surface low number, (b) Atlantic surface low average center pressure (hPa), (c) upper-air low number, and (d) upper-air low average center height (gpm). Values are displayed in the right axis. Bars indicate the winter NAO index (left axis). Correlation coefficients are shown in the lower-left corner. (Winter is defined as Dec-Mar.)

\section{b. NAO influence on detected disturbances}

The NAO variability appears to be a significant factor for the Canary precipitation. Since almost $80 \%$ of the total rainfall has been associated with five disturbance types, its interannual variability can be discussed in terms of the characteristics of these disturbances. The relation between the frequency and average center of ASLs and UALs and the NAO on an annual basis is displayed in Fig. 7. Both kinds of disturbances are significantly deeper during the NAO- phase, but only ASLs are more frequent. NAO- years are usually affected by a lower-than-normal number of UAL. Many of the UALs are cutoff lows not necessarily associated with low SLP; in fact these situations usually present anticyclonic conditions at the surface (Hoskins et al. $1985)$ contributing to $\mathrm{NAO}+$ conditions.

\section{1) Disturbance ASSOciation With RAINFALl AND THE NAO}

In order to estimate the NAO influence over the actual precipitation, the precipitation time series were split into five parts, each one representing the precipitation due to every kind of disturbance.

Table 8 shows the correlation between the split precipitation rainfall series (amount and frequency) and the winter NAO index. It must be pointed out that these values must be calculated for a single-station series and are therefore less representative than the correlation coefficients obtained with the reconstructed series for an entire island. Precipitation due to ASL and TRO disturbances are the most strongly correlated with the NAO. On La Palma and Tenerife (which are representing the four western islands) correlation coefficients are strongly negative, both for precipitation and frequency. Gran Canaria, Fuerteventura, and Lanzarote exhibit only significant correlations for frequency. DALs exhibit a behavior similar to ASLs and TROs on La Palma (affecting both precipitation and frequency) and Fuerteventura and Lanzarote (affecting frequency only). Despite the importance of UAL on total precipitation (over $20 \%$ of total; see Table 5) no significant correlation between its related precipitation and the NAO is detected, but for the TE2 station on frequency. MSLs do 
TABLE 8. Correlation between annual split rainfall time series (prec.) and precipitation days number (freq.) and NAO index. Insignificant correlations are not shown.

\begin{tabular}{|c|c|c|c|c|c|c|}
\hline \multirow[b]{2}{*}{ Station } & & \multicolumn{5}{|c|}{ Disturbance type } \\
\hline & & ASL & MSL & UAL & TRO & DAL \\
\hline \multirow[t]{2}{*}{ LP } & Prec. & $-0.40^{*}$ & - & - & $-0.49 *$ & $-0.53 * *$ \\
\hline & Freq. & $-0.56 * *$ & - & - & $-0.63 * *$ & $-0.48 *$ \\
\hline \multirow[t]{2}{*}{ TE1 } & Prec. & -0.33 & - & - & $-0.35 *$ & -0.31 \\
\hline & Freq. & $-0.50 * *$ & - & - & $-0.53 * *$ & - \\
\hline \multirow[t]{2}{*}{ TE2 } & Prec. & $-0.66 * *$ & - & $+0.44 *$ & -0.36 & - \\
\hline & Freq. & $-0.60 * *$ & - & - & - & - \\
\hline \multirow[t]{2}{*}{ TE3 } & Prec. & $-0.63 * *$ & - & - & $-0.50 * *$ & - \\
\hline & Freq. & $-0.54 * *$ & - & - & $-0.39 *$ & - \\
\hline \multirow[t]{2}{*}{ GC1 } & Prec. & - & - & - & - & - \\
\hline & Freq. & $-0.46^{* *}$ & - & - & - & - \\
\hline \multirow[t]{2}{*}{$\mathrm{GC} 2$} & Prec. & - & - & - & - & - \\
\hline & Freq. & $-0.38^{*}$ & $+0.30^{*}$ & - & $-0.43^{*}$ & - \\
\hline \multirow[t]{2}{*}{ FU } & Prec. & - & - & - & - & - \\
\hline & Freq. & $-0.45^{*}$ & - & - & - & $-0.42^{*}$ \\
\hline \multirow{2}{*}{ LA } & Prec. & - & - & - & - & - \\
\hline & Freq. & $-0.50 * *$ & - & - & -0.33 & $-0.47^{*}$ \\
\hline
\end{tabular}

* $95 \%$ significant correlation.

** $99 \%$ significant correlation.

Unmarked values are $90 \%$ significant.

not exhibit significant variations with the NAO. To sum up, Table 8 indicates that the NAO influence on precipitation and frequency is mainly due to ASLs and TROs (which jointly account for about $34 \%$ of total rainfall average) and preferably on western islands. DALs, which are connected with $21 \%$ of the total precipitation, appear to be related with the NAO only in the two western stations and in Fuerteventura and Lanzarote (frequency). Precipitation due to UAL and MSL does not show significant NAO-associated variability.

The great impact of the NAO on the amount and frequency of winter precipitation is visualized for the different disturbance types in Fig. 8. To obtain it, the five most extreme positive (1961, 1983, 1989, 1990, and 1995) and negative (1963, 1965, 1969, 1979, and

\section{(a) Precipitation}

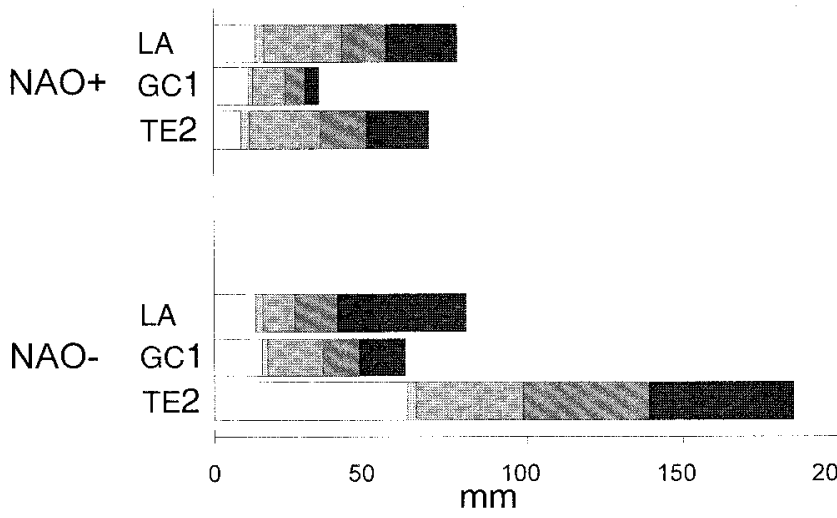

1996) NAO years were selected for the 1955-98 period covered by the NCEP-NCAR reanalysis. As in previous sections, the behavior of the western islands (represented by TE2) differs from that of the eastern ones (represented by LA). As the intermediate case, GC1 has been included.

Over Tenerife, total precipitation during NAOphase is significantly greater, more than double (ANOVA test with $p<0.01$; von Storch and Zwiers 1999), with increases in rainfall associated with every disturbance type but mainly due to ASLs, TROs, and DALs. The effect on the number of precipitation days is not so evident, but there are significant differences for ASLs and TROs. Precipitation frequency on Gran Canaria exhibits a behavior similar to Tenerife. In contrast to that,

\section{(b) Precipitation days}

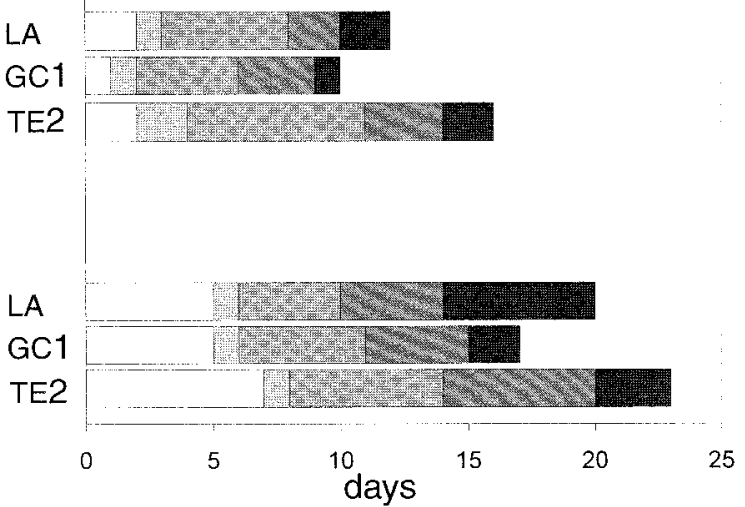

FIG. 8. (a) Comparison of the average winter precipitation and (b) winter precipitation days depending on the NAO phase for three selected daily stations on Tenerife (TE2), Gran Canaria (GC1), and Lanzarote (LA). See Fig. 4 for station location and Table 4 for disturbance type. 
Lanzarote (as Fuerteventura) reveals no difference in the total precipitation amount, but a varied distribution. DAL-associated rainfall is almost double on the negative phase but the difference is almost exactly compensated by the decrease of UAL rainfall. Frequency results for Lanzarote show that NAO + phase has a significantly lower number of precipitation days $(p<0.05)$, due mainly to the decrease of ASL and DAL days; on the contrary, UAL frequency is greater. Although the total rainfall amount does not vary depending on the NAO, this refined study allows identifying some NAO effects even for Lanzarote and Fuerteventura. Their flatter relief requires deep disturbances to produce rainfall, so that DALs are specially relevant for these islands, accounting for almost $30 \%$ of the total precipitation fallen (which in percentage, is almost 2 times more than on the other islands). On NAO- phase, there is an increase in the DAL frequency producing a subsequent increase on its associated rainfall, but this trend is completely compensated by a simultaneous decrease in the frequency (and its associated rainfall) of UALs. Therefore, the NAO probably affects Lanzarote and Fuerteventura in a similar way to the other islands, but the signal is obscured by a combination of several factors: the low rates of rainfall, which make the series noisiest, the opposite contribution of DALs and UALs, and the small variation of the strongly NAO-related ASL rainfall, which, despite a significantly greater frequency of ASL disturbances on the NAO - phase, does not vary in amount (same remark can be made for TRO rainfall).

\section{2) NAO INFLUENCE ON THE DETECTED DISTURBANCES ANOMALY PATTERN}

As seen before, precipitation variation on the Canary Islands is connected to changes in the large-scale circulation. So, the next step was to identify the anomaly patterns associated with every disturbance type, computing the anomaly charts for the five NAO extremes.

For each of the five disturbances, frequency (in occurrence per winter) and SLP or 500-hPa geopotential anomalies (Figs. 9 and 10) were computed for NAO+ and NAO - phase. In order to detect the significance of the differences between the composites, a 1000-trials Monte Carlo test was performed for each grid point.

ASL, TRO (on NAO - phase only), and DAL patterns show a common dipolar structure both for surface and $500 \mathrm{hPa}$. The negative center is over the $35^{\circ}-40^{\circ} \mathrm{N}$ belt on the Canary longitude and a strong positive center over the $55^{\circ}-65^{\circ} \mathrm{N}$ latitudes, thus resembling the NAO dipole but with the symmetry axis in southwest-northeast direction. The dipolar structure is significantly reinforced on NAO- phase for ASL and TRO events. DAL disturbances does not vary significantly depending on the NAO. UAL pattern exhibits a tripolar structure especially on $500 \mathrm{hPa}$, with negative values southeast and northwest of a positive anomaly over the Atlantic around $40^{\circ} \mathrm{N}$, with the maximum varying from east
$(\mathrm{NAO}+)$ to west $(\mathrm{NAO}-)$. UALs do not display a clear surface anomaly over Canaries in spite of being one of the most important rain generators. This agrees with the positive correlation obtained between the UAL frequency and the NAO index. It must be pointed out that ASL anomaly at the 500-hPa level shows a negative center despite it having been defined as a surface low. ASLs are very similar to DALs in nature, differing only by the detection of a low at $500 \mathrm{hPa}$ for DALs. In fact, ASLs usually appear associated with 500-hPa lows too, but they do not fulfill one or more criteria (usually the gradient criteria) to be considered as $500-\mathrm{hPa}$ low systems for the detection procedure. Figure 10b.1 shows a strong negative center but much broader than that corresponding to the DALs (Fig. 10b.5). Last, the MSL anomaly shows the expected negative center over the western Mediterranean. A low center in this position favors a northerly humidity advection toward the $\mathrm{Ca}$ naries. Another significant anomaly zone appears over the Atlantic around $40^{\circ} \mathrm{N}$. All types of disturbances were found to be more frequent during NAO - [up to $+121 \%$ $(p<0.05)$ for ASLs]. The exception is found for UAL, which exhibits $90 \%$ for the same NAO- phase.

Now, it is possible to detail the NAO influence on Canary rainfall. ASL and TRO patterns are deeply NAO influenced. During NAO - phase, ASL disturbances are significantly more frequent and both ASLs and TROs are significantly deeper, showing SLP anomalies very similar to the NAO - pattern. The DAL anomaly is very similar to the NAO dipole as well but does not show significant variation depending on the NAO; because of that, it does not contribute to any rainfall-NAO relationship. Although NAO- phase show a strong negative anomaly over the Canary Islands for UALs, their frequency is significantly lower, canceling the possible effect on precipitation. Moreover, it does not present an NAO pattern. Last, the MSL contribution to the total precipitation is too small to give a clear NAO signal anyway. In any case, its associated pattern does not contribute to a NAO association.

\section{3) ATLANTIC STORM TRACK ANALYSIS}

The NAO influence on the depth and frequency of the disturbances is clear, but what is the physical mechanism involved? Is it simply an intensification of the disturbances? Or does the known NAO-associated shift of the circulation systems depending on the NAO phase (Rogers 1990; Hurrell 1995b; Blender et al. 1997; Serreze et al. 1997) affect the Canary environment? ASLs are evidently deeper and more frequent during NAOyears, which explains the corresponding negative correlation in Table 8 . The same remarks can be said for TROs. An analysis of the storm track based on the filtered geopotential series variance in the 2.5-8-day period (Mukarami 1979; Christoph et al. 1995; Osborn et al. 1999) is shown in Fig. 11 for the five NAO+ and $\mathrm{NAO}-$ extremes for surface (Figs. 11a.1-11a.2) and 
(a.1) ASL (NAO+) $f=5.6$

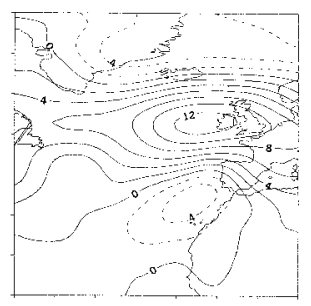

(b.1) ASL (NAO-) $f=12.4^{* *}$

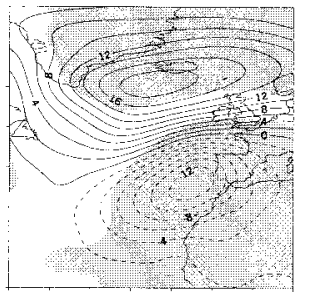

(a.2) MSL (NAO+) f $=2.6$

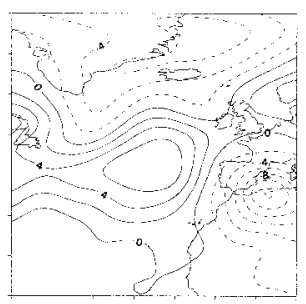

(b. 2) MSL (NAO-) $\quad \mathrm{f}=3.8$

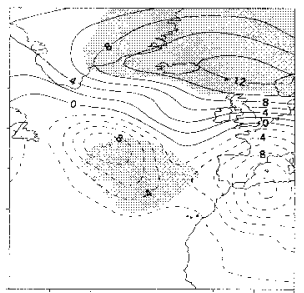

(a.3) UAL $(\mathrm{NAO}+) f=18.0$

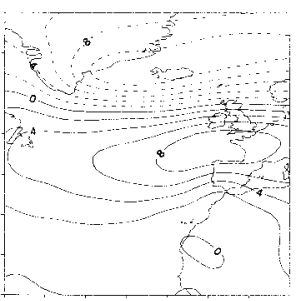

(b.3) UAL (NAO-) $f=9.2^{*}$

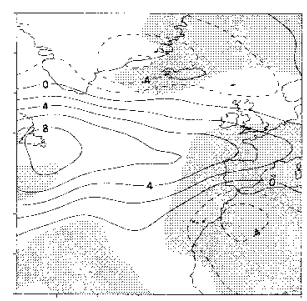

(a.4) TRO (NAO+) $\mathrm{f}=7.6$

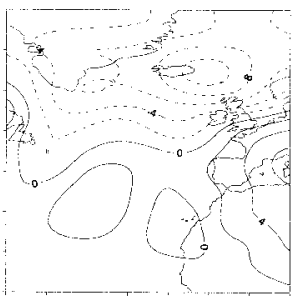

(b.4) $T R O$ (NAO-) $f=9.8$

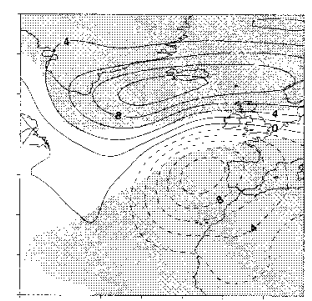

(a.5) DAL (NAO+) $\quad f=3.2$

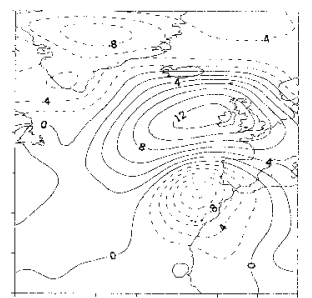

(b.5) DAL (NAO-) $\quad \mathrm{f}=4.8$

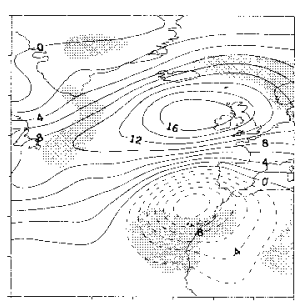

FIG. 9. (a.1)-(a.5) SLP winter anomaly pattern for detected disturbances on the NAO+ and (b.1)-(b.5) NAO- phases. Contour interval is $2 \mathrm{hPa}$; negative values are dashed. Shaded areas in (b.1)-(b.5) indicate significant differences between the NAO + and NAO - phases $(p$ $<0.05$ ). The relative frequency $f$ of the disturbance events (in event number per winter) is also shown in the upper-right corner. Frequency significant differences are marked in (b.1)-(b.5) with $* *(p<0.05)$ or $*(p<0.10)$.

$500 \mathrm{hPa}$ (Figs. 11b.1-11b.2). The 2.5-8-day window corresponds to the typical lifetime of the detected disturbances.

Most of the North Atlantic cyclonic activity is restricted to the high latitudes between $50^{\circ}$ and $70^{\circ} \mathrm{N}$ as well at the surface as at $500 \mathrm{hPa}$. The maximum variance is located more than $30^{\circ}$ northward of the Canary latitude. The averaged surface low number over the influence area (over a great extension of about 3000000 $\mathrm{km}^{2}$; see section 2 and Fig. 8) is only 12 disturbances per year with a central-averaged pressure greater than $1006 \mathrm{hPa}$. Corresponding values on $500 \mathrm{hPa}$ for UAL and TRO are 21 and 23 disturbances per year. So, surface low centers very rarely affect the Canary area directly, especially at the surface, making the area so sensitive to circulation changes that scarcely perceptible differences in the surface storm track over the Canary Islands during the different NAO phases can be enough to explain the observed differences. On surface, NAO+ phase shows a sharp maximum deviation following the southwest-northeast direction. During NAO- years, the same configuration can be seen, but the structure is not as well defined, and the north-south gradient is lower. In order to detect the maximum variation area between (a.1) $A S L(N A O+) f=5.6$

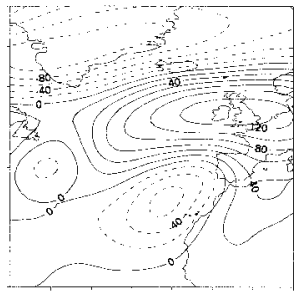

(b. 1) ASL (NAO-) $f=12.4^{* *}$

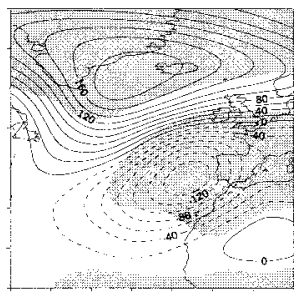

(a.2) MSL (NAO+) $f=2.6$

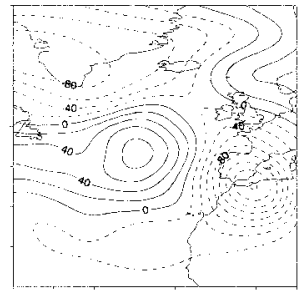

(b.2) MSL (NAO-) $f=3.8$

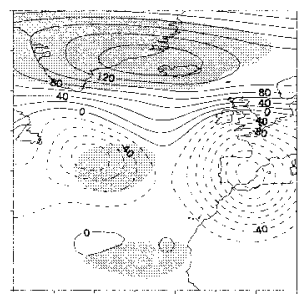

(a.3) UAL (NAO+) $f=18.0$

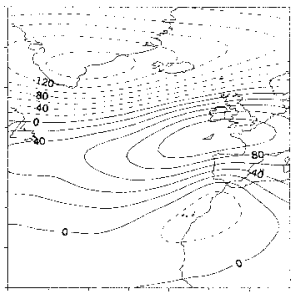

(b.3) UAL (NAO-) $f=9.2^{*}$

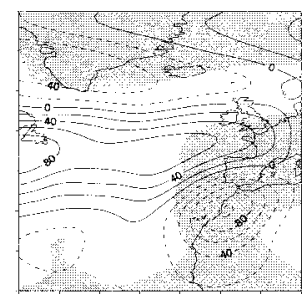

(a.4) TRO (NAO+) $\quad \mathrm{f}=7.6$

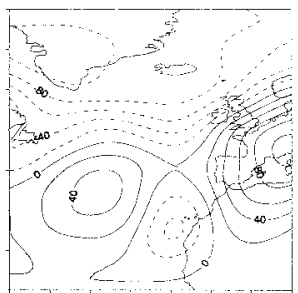

(b.4) TRO (NAO-) $f=9.8$

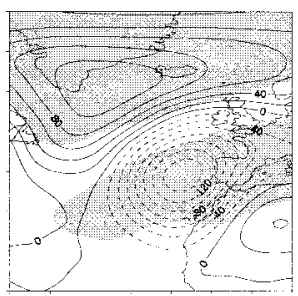

(a.5) DAL (NAO+) $\quad f=3.2$

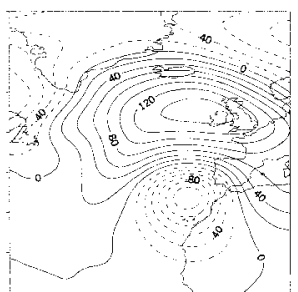

(b.5) DAL (NAO-) $\quad f=4.8$

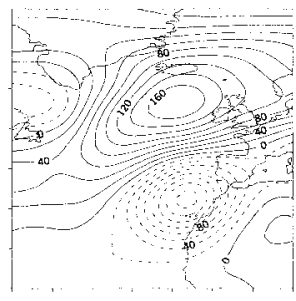

FIG. 10. As Fig. 9 but for $500 \mathrm{hPa}$. Contour interval is $20 \mathrm{gpm}$. 
(a.1) NAO+ Surface storm track

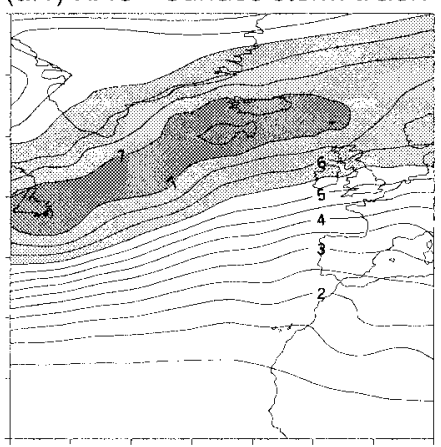

(b. 1) $\mathrm{NAO}+500-\mathrm{hPa}$ storm track

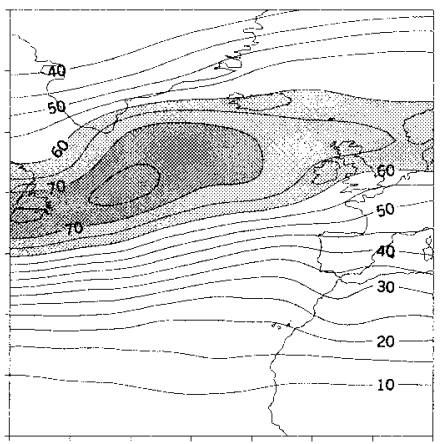

(a.2) NAO- Surface storm track

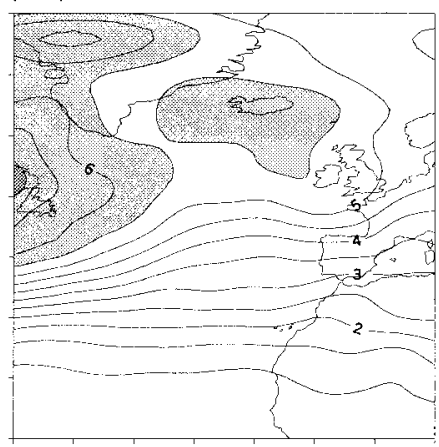

(b.2) NAO- 500-hPa storm track

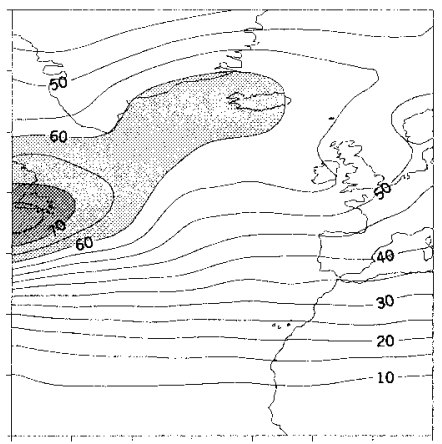

(a.3) NAO-/NAO+ (in \% of NAO+)

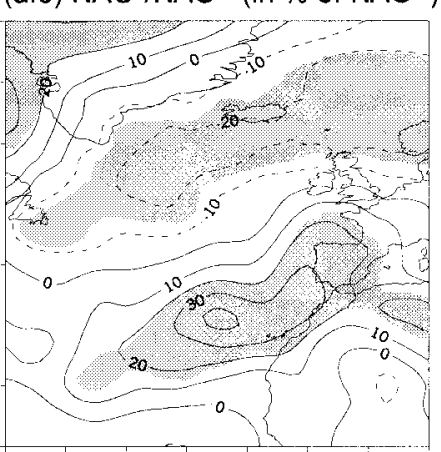

(b.3) NAO-/NAO+ (in \% of NAO+)

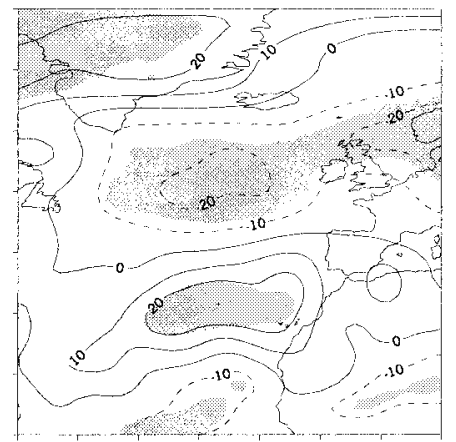

FIG. 11. Atlantic storm track based in the std dev of filtered SLP [(a.1) for the NAO+ phase and (a.2) for the NAO- phase] and (b.1), (b.2) 500-hPa height. Contours are $1 \mathrm{hPa}$ for surface and $5 \mathrm{gpm}$ for $500 \mathrm{hPa}$. (a.3), (b.3) The difference between the NAO- and NAO+ storm track computed as $100 \%[(\mathrm{NAO}-)-(\mathrm{NAO}+)] /(\mathrm{NAO}+) ; 99 \%$ significant differences are shaded (1000-trials Monte Carlo test).

the opposite NAO phases, the difference between $\mathrm{NAO}-$ and $\mathrm{NAO}+$ storm track computed in percent of the NAO+ value (Figs. 11a.3 and 11b.3) shows that the maximum variability increment in $\mathrm{NAO}-$ phase is located exactly over the Canary influence area. This increase reaches $40 \%$ at the surface during NAO- years while over the North Atlantic, above $55^{\circ} \mathrm{N}$, values are nearly $20 \%$ lower. At the $500-\mathrm{hPa}$ level the situation is similar but the increment above the Canary Islands is not as pronounced (about 20\%).

\section{Discussion}

The results obtained provide direct evidence of the NAO influence on an area as far south as the Canary Islands. A significant negative correlation between the NAO and the rainfall of this subtropical region has been found, being one of the most southern areas where a direct NAO influence has been documented up to date along with the western Moroccan coast (Lamb and Peppler 1987; Ward et al. 1999). The correlation between rainfall and SLP show that the standard NAO index is an optimal indicator for the Canarian precipitation, especially on the western islands. The classification of the synoptic disturbances leading to precipitation and their NAO relationships along with the detection of significant variations in the storm tracks provides a further step for understanding the underlying mechanism of the interannual variability of rainfall.

Roughly $75 \%$ of the total rainfall is produced by two main mechanisms: high-level disturbances, which can be closed lows (UALs) or troughs (TROs), and Atlantic lows, which can affect the entire troposphere (DALs) or preferably at low levels (ASLs). A secondary disturbance related with the presence of surface lows over the western Mediterranean area (MSLs) has been found to contribute only about $3 \%$ to the total rainfall.

There are significantly more and deeper surface lows (ASLs) during NAO- years. These disturbances are accompanied by one or two of the following situations: 1) an intensified advection that occurs south of the low cores, breaking the inversion layer and providing abundant wet air and 2) the effect of the frontal tails associated to northern lows. The southward displacement and intensification of cyclone activity in the mid-Atlantic sector (from $40^{\circ}$ to $60^{\circ} \mathrm{N}$ ) on $\mathrm{NAO}-$ phase has been documented in several previous papers (Serreze et al. 1997; Rogers 1997). Therefore, this work agrees with the precedent studies but extends the area of increasing cyclone activity as far south as the $30^{\circ}-40^{\circ} \mathrm{N}$ latitude belt over the Canary longitude. The relation between TROs and the NAO was not a priori expected, but it has been well established. These disturbances are as- 
sociated with the presence of cold air in high levels and the subsequent destabilization of the air column (along with the break of the inversion layer). The 500-hPa geopotential anomaly for this disturbance shows that the trough is $100 \mathrm{gpm}$ deeper during NAO- years. Despite the fact that disturbance frequency is not significantly greater, the enhanced instability causes more intense rainfall per event. It could be argued that the anomaly on $500 \mathrm{hPa}$ does not explain the NAO correlation because the NAO index is computed from SLP. However, the SLP anomaly for TRO pattern shows a NAO dipole on surface on NAO-, which does not appear on NAO+. Thus the intensification of the TRO disturbance implies anomalous SLP that contributes to a negative value of the NAO index.

UAL- and DAL-related precipitation does not appear connected with the NAO. UAL disturbances are even significantly less frequent on $\mathrm{NAO}-$. So, although the $\mathrm{UAL}$ disturbance is deeper on $\mathrm{NAO}-$, the related rainfall does not increase significantly. The DAL pattern does not vary depending on the NAO phase, neither in frequency nor in intensity. This result was unexpected; DALs imply an SLP anomaly even stronger than the NAO-connected ASL-both of them resembling the NAO negative phase. However, there are not significant changes on the DAL pattern, although the dipole is slightly deeper and frequent during NAO-. The DALrelated rainfall (Table 8) exhibits the expected NAO relationship on LP and TE1 stations. On the other hand, FU and LA stations exhibit the same behavior for ASL precipitation (frequency-NAO negative correlation). This suggests that DAL disturbances could be related to the NAO in the same sense as ASL, but the lower number of DAL events in the sample makes the result not representative.

Previous studies have related the southward displacement of midlatitude disturbances with atmospheric blocking episodes, which are closely linked with the NAO (Walker and Bliss 1932; Barnston and Livezey 1987). Our results suggest that the NAO influence is different depending on disturbance type. ASL events are more frequent and intense on NAO- phase, whereas DAL disturbances do not exhibit this variability so clearly. Likewise, two similar disturbances such as UAL and TRO present a very different NAO relationship. More investigation should be done in this respect.

Two geographical clusters can be distinguished according to their NAO relationship. 1) The five western islands (Hierro, La Palma, Gomera, Tenerife, and Gran Canaria) form one. Their common characteristic is high relief, which amplifies any atmospheric disturbance, making these islands very sensitive to weather variations that do not produce rainfall over flatter terrain. The five islands exhibit a strong NAO-rainfall connection, which mainly stems from ASL- and TRO-associated rainfall. The DAL relation is detected on La Palma and Tenerife only. In general, the NAO relationship gets weaker from west to east. 2) Lanzarote and Fuer- teventura are much flatter islands and need deeper disturbances to experience rainfall. Therefore, DAL disturbances are specially important, providing $30 \%$ of the total rainfall. These islands do not show any NAO relationship in the total rainfall series, but a detailed analysis reveals that the important DAL-associated rainfall-which in this case appears connected with the NAO through the frequency-is more than double in $\mathrm{NAO}-$ years. However, this increment is exactly compensated for by an equivalent decrease of the UAL rainfall, thus canceling any possible NAO effects.

The physical mechanism controlling the NAO influence over the Atlantic rainfall is the southward displacement of the whole circulation system during $\mathrm{NAO}-$ phase. However, in the Canary case, the analysis of the storm tracks could not be enough to properly represent the interannual changes in the variability of the geopotential. This subtropical area is characterized by a great stability due to the presence of the Azores high all year and a very low frequency of transient disturbances (about 10-20 events per year). Moreover, the disturbances at this latitude are relatively shallow, with an average center pressure of about $1006 \mathrm{hPa}$ at surface or a height of $5585 \mathrm{~m}$ for $500-\mathrm{hPa}$ lows. These factors explain that the storm track interannual changes are not easily detectable in these latitudes. However, a detailed comparison (Fig. 11) proves that the Canarian area exhibits the maximum increment in the variance band from 2.5 to 8 days between $\mathrm{NAO}+$ and NAOyears both for surface and $500 \mathrm{hPa}$.

Acknowledgments. The authors wish to thank to the two anonymous referees for their useful comments, which have contributed to the improvement of the quality and presentation of this work. This study is supported by the Spanish Comisión Interministerial de Ciencia y Tecnologia under Grant CLI98-0649.

\section{REFERENCES}

Barnston, A. G., and R. E. Livezey, 1987: Classification, seasonality and persistence of low-frequency atmospheric circulation patterns. Mon. Wea. Rev., 115, 1083-1126.

Blender, R., K. Fraedrich, and F. Lunkeit, 1997: Identification of cyclone-track regimes in the North Atlantic. Quart. J. Roy. Meteor. Soc., 123, 727-741.

Christoph, M., U. Ulbrich, and U. Haak, 1995: Faster determination of the intraseasonal variability of storm tracks using Murakami's recursive filter. Mon. Wea. Rev., 123, 578-581.

Folland, C. K., T. N. Palmer, and D. E. Parker, 1986: Sahel rainfall and worldwide temperatures, 1901-1985. Nature, 320, 602-607.

Font, I., 1956: El Tiempo Atmosferico en las Islas Canarias. Servicio Meteorologico Nacional, $96 \mathrm{pp}$.

Gallego, D., R. García, E. Hernández, L. Gimeno, and P. Ribera, 2001: An ENSO signal in the North Atlantic subtropical area. Geophys. Res. Lett., 28, 2939-2942.

Gibson, J. K., P. Kallberg, S. Uppala, A. Hernandez, A. Nomura, and E. Serrano, 1997: ERA description. ECMWF Re-analysis Project Report Series 1, ECMWF, Reading, United Kingdom, 66 pp.

Hoskins, B. J., M. E. McIntyre, and A. W. Robertson, 1985: On the use and significance of isentropic potential vorticity maps. Quart. J. Roy. Meteor. Soc., 111, 877-946. 
Hurrell, J. W., 1995a: Decadal trends in the North Atlantic oscillation regional temperatures and precipitation. Science, 269, 676-679.

- 1995b: Transient eddy forcing of the rotational flow during northern winter. J. Atmos. Sci., 52, 2286-2301.

_, 1996 : Influence of variations in extratropical wintertime teleconnections on Northern Hemisphere temperature. Geophys. Res. Lett., 23, 685-668.

Jones, P. D., T. Jonsson, and D. Wheeler, 1997: Extension to the North Atlantic Oscillation using early instrumental pressure observations from Gibraltar and south-west Iceland. Int. J. Climatol. 17, 1433-1450.

Kalnay, E., and Coauthors, 1996: The NCEP/NCAR 40-Year Reanalysis Project. Bull. Amer. Meteor. Soc., 77, 437-471.

Kushnir, Y., and J. M. Wallace, 1989: Low-frequency variability in the Northern Hemisphere winter: Geographical distribution, structure and timescale dependence. J. Atmos. Sci., 46, 3122 3142.

Kutzbach, J. E., 1967: Empirical eigenvectors of sea-level pressure, surface temperature and precipitation complexes over North America. J. Appl. Meteor., 6, 791-802.

Lamb, P. J., 1978: Large-scale tropical Atlantic circulation patterns associated with subsaharan weather anomalies. Tellus, 30, 240251.

— and an application. Bull. Amer. Meteor. Soc., 68, 1218-1225.

Molinari, R. L., D. A. Mayer, J. F. Festa, and H. F. Bezdek, 1997 Multi-year variability in the near-surface temperature structure of the midlatitude western North Atlantic Ocean. J. Geophys. Res., 102, 3267-3278.

Moses, T., G. N. Kiladis, H. F. Diaz, and R. G. Barry, 1987: Characteristics and frequency reversals in mean sea level pressure in the North Atlantic sector and their relationships to long-term temperature trends. J. Climatol., 7, 13-30.

Murakami, M., 1979: Large-scale aspects of deep convective activity over the GATE area. Mon. Wea. Rev., 107, 994-1013.

Osborn, T. J., K. R. Briffa, S. F. B. Tett, P. D. Jones, and R. M. Trigo, 1999: Evaluation of the North Atlantic Oscillation as simulated by a coupled climate model. Climate Dyn., 15, 685-702.

Parker, D. E., and C. K. Folland, 1988: The nature of climate variability. Meteor. Mag., 117, 201-210.

Peixoto, J. P., and A. H. Oort, 1992: Physics of Climate. American Institute of Physics, $520 \mathrm{pp}$.
Preisendorfer, R. W., 1988: Principal component analysis in meteorology and oceanography. Developments in Atmospheric Sciences, C. D. Mobley, Ed., Vol. 17, Elsevier, 425 pp.

Reverdin, G., D. R. Cayan, and Y. Kushnir, 1997: Decadal variability of hydrography in the upper northern North Atlantic, 1948-1990. J. Geophys. Res., 102, 8505-8533.

Rogers, J. C., 1990: Patterns of low-frequency monthly sea level pressure variability (1899-1986) and associated wave cyclone frequencies. J. Climate, 3, 1364-1379.

__ 1997: North Atlantic storm track variability and its association to the North Atlantic oscillation and climate variability of northern Europe. J. Climate, 10, 1635-1647.

Serreze, M. C., F. Carse, R. G. Barry, and J. C. Rogers, 1997: Icelandic low cyclone activity: Climatological features, linkages with the NAO, and relationships with recent changes in the Northern Hemisphere circulation. J. Climate, 10, 453-464.

Trigo, I. F., T. D. Davies, and G. R. Bigg, 1999: Objective climatology of cyclones in the Mediterranean region. J. Climate, 12, 16851696.

Ulbrich, U., M. Christoph, J. G. Pinto, and J. Corte-Real, 1999: Dependence of winter precipitation over Portugal on NAO and baroclinic wave activity. Int. J. Climatol., 19, 379-390.

van Loon, H., and J. Williams, 1976: The connection between trends of mean temperature and circulation at the surface. Part I: Winter. Mon. Wea. Rev., 104, 365-380.

between Greenland and northern Europe. Part I: General description. Mon. Wea. Rev., 106, 296-310.

von Storch, H., and F. W. Zwiers, 1999: Statistical Analysis in Climate Research. Cambridge University Press, 484 pp.

Walker, G. T., and E. W. Bliss, 1932: World weather V. Mem. Roy. Meteor. Soc., 4, 53-84.

Wallace, J. M., Y. Zhang, and J. A. Renwick, 1995: Dynamic contribution to hemispheric mean temperature trends. Science, 270, 780-783.

Ward, M. N., P. J. Lamb, D. H. Portis, M. El Hamly, and R. Sebbari, 1999: Beyond El Niño: Decadal and Interdecadal Climate Variability. Springer, $374 \mathrm{pp}$.

Zorita, E., V. Kharin, and H. von Storch, 1992: The atmospheric circulation and sea surface temperature in the North Atlantic area in winter: Their interaction and relevance for Iberian precipitation. J. Climate, 5, 1097-1108. 